\title{
Preface to the special issue on seismic array analysis and CEArray*
}

\author{
Fenglin Niu* \\ Department of Earth Science, Rice University, Houston, TX 77005, USA
}

\begin{abstract}
A seismic array is a set of seismographs being arranged in a regular geometric pattern to improve signalto-noise ratio (SNR). Seismic arrays at various length scales have been introduced since early 1960s and have been proved to be superior to single three-component stations for detecting and characterizing signals from earthquakes and explosions. The better detection capability of arrays is achieved with a so-called "beamforming" technique, which suppress noises while preserving signals, thus enhancing SNR. The "beamforming" technique also estimates the wave vector, i.e., backazimuth and apparent velocity of an incoming signal, which is crucial in identifying the signal, e.g., whether it is a $\mathrm{P}, \mathrm{S}$, local, regional or teleseismic wave. The Norwegian Seismic Array (NORSAR) was built in 1968, and was one of the earliest short-period seismograph arrays in the world. Doornbos and Husebye (1972) used it to measure apparent velocities of PKP precursors and found that scattering in the lowermost mantle is likely the cause of the enigmatic precursors.
\end{abstract}

A key requirement for array data processing is the high signal coherency across the array. Based on this, a local or regional seismic network can be considered as a seismic array, as long as the recorded signals are highly coherent across the network, which is usually true in most cases. Benz and Vidale (1993) used approximately 700 short-period vertical-component seismic stations operated in California by the US Geological Survey and the California Institute of Technology as a largeaperture array and studied the underside reflections from the $410-\mathrm{km}$ and $660-\mathrm{km}$ seismic discontinuities of high frequency $\mathrm{P}$ waves. They found a very sharp 410-km which puts very strong constraints on the composition of the upper mantle and on the details of the

\footnotetext{
* Received 10 January 2011; accepted in revised form 11 January 2011; published 10 February 2011.

* Corresponding author. e-mail: niu@rice.edu

(C) The Seismological Society of China and Springer-Verlag Berlin Heidelberg 2011
}

olivine-wadsleyite phase change. Kawakatsu and Niu (1994) used the J-array, which consists of more than 300 short-period vertical-component seismographs, to detect a weak $\mathrm{P}$ to $\mathrm{S}$ converted signal from a deep mantle reflector. All these studies suggested that large-scale regional seismic networks could be a powerful "telescope" to view the Earth's interior. But in the 1990s, California and Japan are probably the only two places where regional seismic networks were dense enough for array data analysis.

Due to the introduction of digital data acquisition system, together with the rapid progress in computational capability in the 1990s, it has become easier to record and process the large amount of data from a seismic array. Thus the first decade of the 21-centry witnessed a rapid expansion of seismic arrays all over the globe, with more and more instruments covering a broader and broader area of Earth's surface. In US, starting from 2005, 400 broadband seismographs have been used to sweep across the entire United States in a ten-year period, which forms a gigantic array known as the USArray. In Japan, since the beginning of 2001, more than 700 seismic stations have been installed in boreholes a few hundreds meters below surface. In China, the China Earthquake Administration (CEA) has gradually upgraded and expanded its national and regional networks since the late $1990 \mathrm{~s}$ in order to better monitor the seismic activity. Currently, CEA operates the largest permanent seismic network in the world, which consists of a backbone national seismograph network (CNDSN), 31 regional networks, and several small aperture arrays with more than 1000 stations including $850+$ broadband stations (Zheng et al., 2009). The $1000+$ stations formed a large 2D areal array (hereafter CEArray) with an aperture $\sim 6700 \mathrm{~km}$ from east to west and $\sim 3500 \mathrm{~km}$ from north to south. Station spacing varies drastically with location and reaches to $\sim 20-100 \mathrm{~km}$ in the eastern and central parts of China. While the CEArray is anticipated to play an important 
role in monitoring seismic activities, mapping rupture details of large earthquakes, providing early warning, seismic risk assessment and mitigation in China, it also opens a new era for imaging Earth's interior as well as studying earthquake rupture and fault zone processes.

In this issue, we publish 13 articles that used different types of arrays located in the different part of the world. They revealed many interesting structures within the Earth, from crust to the base of the mantle. Three studies conducted on the crustal structure in Northeast China (Chen et al., Liu and Niu, Ai and Shen) using different seismic networks provided a consistent picture of the region with complementary information. Chen et al. used the national seismic network data and found a dipping structure associated with the Suolon suture from several stations located near the suture. Liu and Niu analyzed data from six seismic networks in the region and found the Moho beneath the eastern flank of the Songliao Basin and the Changbaishan region, east to the Suolon suture, is dynamically uplifted by a likely upwelling in the upper mantle. On the other hand, Ai and Shen analyzed data recorded by a temporal seismic array deployed at the southeast edge of the Songliao Basin and obtained a high-resolution map of the area, which appears to be consistent with the results of Liu and Niu.

Zhai and Levander found reverberation from the sedimentary layer could interfere with Moho conversion waves, making it hard to interpret receiver function data. They found some evidence from data recorded by the BOLIVAR array deployed in the eastern Venezuela. Yang et al. developed a method that jointly inverts earthquake surface wave and ambient noise data. The method can significantly improve the depth resolution in surface tomography. They applied it to the USArray and suggested that it could be also applied to the CEArray.

The unparallel power of the CEArray is fully revealed by the two studies of Wang and Niu. The first study applied receiver function imaging technique to the CEArray data and clearly imaged the subducted Cretaceous Pacific Plate beneath the east of China. They found a double-branched $660-\mathrm{km}$ discontinuity within the core of the slab, which could provide strong constraints on the physical and chemical state within a subducted slab. The second study of Wang and Niu modeled $\mathrm{P}$ waveform data recorded by the CEArray and found a very broad $660-\mathrm{km}$ discontinuity, which has significant implication on deep subduction process. Vanacore and Niu used SKS and SKKS data recorded by the BOLIVAR array mentioned above and found that the Galapagos hotspot has a deep origin at the core-mantle boundary.

Three papers used the data of the Sichuan regional seismic network and temporal deployment after the 2008 M7.9 Wenchuan earthquake to study the Longmenshan fault system. Chen et al. found 11 repeating earthquake sequences along the fault. They further used these sequences to estimate the in-situ slip rates at seismogenic depths and found that the deep slip rates are much larger than those observed at Earth's surface. The observation of increasing slip rates with depth could have significant implications in assessing risk of seismic hazard. Zhao et al. relocated the aftershock with a double difference method and found that the back-range fault mainly induced and controlled the aftershock occurrence in the northern section of aftershocks sequence. Finally, Cai et al. determined focal mechanisms of 89 large aftershocks and found that the principle compressional direction of the stress field is subhorizontal. They further argued that the absent of reverse faulting is inconsistent with a scenario of an inflated crust due to extrusion of lower crust material from the Tibetan Plateau to the margin.

While the special issue was intended to bring aspects of state-of-art in array seismology, I also hope it is useful to the community in their research during the second decade of the 21st century with the expanding CEArray.

Finally, I would like to thank all the authors for their timely contributions, and to the reviewers for their careful and constructive comments. From the Earthquake Science I thank Dr. Lili Tian, the acquisition editor of this special editor, who showed incredible patience in helping produce this special issue.

\section{References}

Benz H M and Vidale J E (1993). Sharpness of uppermantle discontinuities determined from high-frequency reflections. Nature 365: 147-150.

Doornbos D J and Husebye E S (1972). Array analysis of PKP phases and their precursors. Phys Earth Planet Inter 5: 387-399.

Kawakatsu H and Niu F (1994). Seismic evidence for a 920$\mathrm{km}$ discontinuity in the mantle. Nature 371: 301-305.

Zheng X F, Ouyang B, Zhang D N, Yao Z X, Liang J H and Zheng J (2009). Technical system construction of Data Backup Centre for China Seismograph Network and the data support to researches on the Wenchuan earthquake. Chinese J Geophys 52: 14121417, doi:10.3969/j.issn.0001-5733 (in Chinese with English abstract). 